\title{
Advanced computational methods of perpendicularly loaded laminated glass panes
}

\author{
Tomáš Hána ${ }^{1}$, Miroslav Vokáč ${ }^{2}$, Martina Eliášová ${ }^{3}$, Klára V. Machalická ${ }^{4}$ \\ 1, 2, ${ }^{4}$ Klokner Institute, Czech Technical University, Prague, Czech Republic \\ ${ }^{3}$ Faculty of Civil Engineering, Czech Technical University, Prague, Czech Republic
}

\section{E-mail: 'tomas.hana@fsv.cvut.cz (corresponding author)}

\begin{abstract}
Various examples of glass load bearing structures such as beams, columns, panes, or even stairs are used in a current architecture. For safety reasons, these members are mostly made of laminated glass. Polymeric interlayers are used for glass plates bonding and their shear stiffness, as a time-temperature dependent parameter, meaningly influences the response of the entire perpendicularly loaded laminated glass pane. Even though the shear stiffness of the interlayer is available, the exact stress-state analysis of the pane is rather challenging. This paper compares the results of perpendicularly loaded double laminated glass panes at various boundary conditions, calculated by current advanced analytical methods and by the draft of the European standard prEN 16612 to the numerical simulation performed in RFEM 5 ${ }^{\circledR}$. Important differences between these methods are illustrated. Futher recommendations for a design of these structures in practice are also provided.
\end{abstract}

Keywords: laminated glass, shear stiffness, polymeric interlayer, advanced methods.

\section{Introduction}

Laminated glass, i.e., a composition of two or more glass plates bonded by transparent polymeric interlayer, is currently designed as load bearing structural element. The examples of such structures are glass panes, balustrades, marchionesses, or even stairs. Response of these structures in bending is a subject of an intensive research (Serafinavičius, Lebet, Louter, Lenkimas, \& Kuranovas, 2013; Louter, 2011). Laminated glass is currently preferred prior to the use of monolithic glass because of its post-breakage performance. Glass is a brittle material with a risk of a sudden collapse. Structure users may be thus endangered by falling shards or by other injuries when monolithic glass is overloaded. Polymeric interlayer in a laminated glass is able to keep the shards attached and enables to ensure some residual post-breakage capacity of a pane because remaining glass plates are able to carry part of the load. This situation has been even incorporated into some national standards for the design of laminated glass (DIN 18008-1, 2010). In the intact laminated pane, the interlayer itself cannot provide sufficient flexural stiffness, but it enables to transfer the shear stress between the individual glass plates due to its shear stiffness. Thus, glass plates interact in bending and tend to carry the load together. Shear stiffness of the interlayer principally depends on the ambient temperature and on the load duration since polymeric interlayers are highly visco-elastic materials. This quantity must be experimentally verified (Schneider, Langer, \& Schuster, 2015). When the shear stiffness of the interlayer is negligible, glass plates in the pane do not interact and carry the load separately (layered pane), see Figure 1a. On the other hand, when the shear stiffness is sufficient, glass plates are fully shear coupled (monolithic pane), as shown in Figure 1b. Currently, there is not any official uniform European standard for laminated glass enabling a designer to consider such shear coupling of glass plates in bending which results in excessively robust structures. To capture this coupling, a full three-dimensional FEM analysis is possible, but it requires certain modeling skills, exact boundary conditions, and it is rather time consuming. Because of this, improved analytical methods have been recently developed. These are based on the so called "effective thickness", i.e., the thickness of a monolithic pane with equivalent bending properties as a $j$-th glass plate in a laminated pane at the identical boundary conditions.

Commonly used improved method is, e.g., Wölfel-Bennison method which has been included into American standards (ASTM: E1300-09, 2009). Another more general method is called Enhanced Effective Thickness as a part of Italian standards for laminatd glass (CNR-DT-210, 2012). On the European level, there has been such effort to make the uniform standard for the design of load bearing laminated glass structures taking the shear coupling of glass plates into account. This has resulted into the draft of the standard "Glass in building - Determination of the load resistance

(C) 2019 Authors. Published by VGTU Press. This is an open-access article distributed under the terms of the Creative Commons Attribution (http://creativecommons.org/licenses/by/4.0/) License, which permits unrestricted use, distribution, and reproduction in any medium, provided the original author and source are credited. 
of glass panes by calculation and testing" (prEN 16612, 2013) which was originally developed for non-load bearing structures such as windows or in-fill glazings. In practice, laminated glass panes are usually linearly supported but in case of point-fixings, no analytical method is able to capture the exact stress concentrations around holes or at contact points thus FEM analysis is the only way to be used. This paper aims at the case study of the effective thickness determination in case of double laminated glass pane at various boundary conditions using current analytical methods and numerical simulation performed in software RFEM $5 \AA$. Main differences between these methods are commented and further recommendations for a design of these structures in practice are provided.

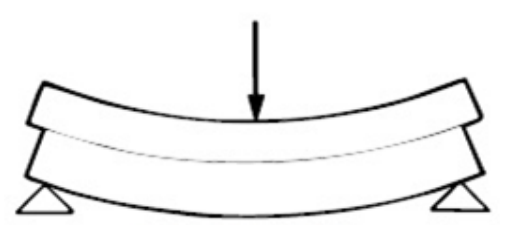

a) layered pane

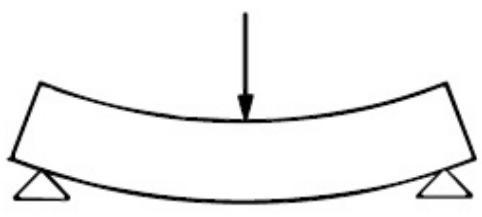

b) monolithic pane

Figure 1. Boarder cases of laminated glass pane in practice

\section{Summary of current analytical methods used for a design of laminated glass}

\section{European Standard prEN 16612}

This standard was originally developed for the design of non-load bearing short-term loaded secondary structures such as windows or infill-glazings. These are usually continuously simply supported structures loaded by wind. In spite of its original purpose, civil engineers tend to use this document for all load bearing laminated glass structures. The document assesses the $j$-th glass plate in the pane with its equivalent effective thickness depending on the loading case considered just only in terms of a load duration and ambient temperature. This conversion is made through the coefficient of shear forces transfer $\omega$ tabulated in this document. The coefficient takes the values from 1.0 (full shear coupling) to 0 (glass plates sliding). Its certain value is determined according to the appropriate "stiffness family" of the interlayer which can be found in a related document aimed at mechanical properties of interlayers (prEN 16613, 2013). The effective thickness of $j$-th glass plate is determined separately for deflection $h_{e f, w}$ and normal stress $h_{j, e f, \sigma}$ calculation according to the Eq. (1) and Eq. (2) as

$$
\begin{gathered}
h_{e f, w}=\sqrt[3]{\sum_{j} h_{j}^{3}+12 \cdot \omega \cdot\left(\sum_{j} h_{j} \cdot h_{m, j}^{2}\right)} ; \\
h_{j, e f, \sigma}=\sqrt[2]{\frac{h_{e f, w}^{3}}{h_{j}+2 \cdot \omega \cdot h_{m, j}}},
\end{gathered}
$$

where: $\omega$ - coefficient of shear forces transfer [-]; $h_{j}$ - thickness of the individual glass plate $[\mathrm{mm}] ; h_{m, j}-$ distance of the midpane of the $j$-th glass plate from the midpane of the laminated pane [mm].

\section{Wölfel-Bennison method $(W-B)$}

This method was originally intended for the calculation of sandwich structures consisting of two external layers with sufficient axial stiffness and the soft-core layer providing shear stiffness only. This is the case of sandwich panels. Wölfel's approach was later extended by S. J. Bennison for the determination of the effective thickness of onedimensional laminated glass panes (e.g. roof panels) depending on the coefficient of shear forces $\Gamma$. This coefficient represents a measure of the shear forces transfer through the interlayer. It varies from 0 to 1.0 and it depends directly on the value of the interlayer's shear stiffness $G$. The analytical relation for $\Gamma$ is as follows (Bennison \& Stelzer, 2009):

$$
\Gamma=1 /\left(1+\beta \cdot \frac{t \cdot E}{b \cdot G \cdot l^{2}} \cdot \frac{A_{1} \cdot A_{2}}{A_{1}+A_{2}}\right),
$$

where: $t$ - thickness of the interlayer [mm]; $E$ - Young's modulus of glass [MPa]; $G$ - shear stiffness modulus of the interlayer [MPa]; $l$ - length of the pane $[\mathrm{mm}] ; b$ - width of the cross-section $[\mathrm{mm}] ; A_{i}-$ denotes the area of the individual glass plate in the cross-section $\left[\mathrm{mm}^{2}\right]$; and $\beta-$ coefficient related to boundary conditions of a laminated glass structure [-].

Civil engineers often simplify Bennison's approach by taking the universal value of $\beta=9.6$ (Calderone, Davies, Bennison, Huang, \& Gang, 2009) for the two-dimensional case of laminated panes in various boundary conditions and even use this method for the calculation of stress at contact points. Although in the original Wölfel's theory, this value 
was suitable for one-dimensional case of pane under uniformly distributed load. The example of this pane with the designation of input parameters for calculation is shown in Figure 2.

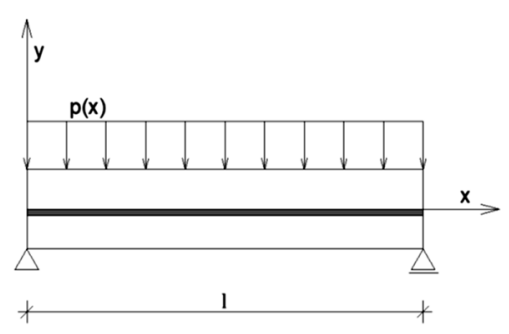

a) simply supported pane

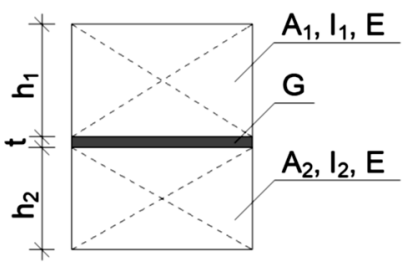

b) important values of cross section

Figure 2. Input parameters for the calculation of stress and deflection effective thickness of one-dimensional double laminated glass pane by W-B method

The effective thickness of the deflection $h_{e f, w}$ and normal stress $h_{j, e f, \sigma}(j \in\{1,2\})$ are calculated according to the Eq. (4) and Eq. (5) (Galuppi, Manara, \& Carfagni, 2012a)

$$
\begin{gathered}
h_{e f, w}=\sqrt[3]{h_{1}^{3}+h_{2}^{3}+12 \cdot \Gamma \cdot I_{s}} ; \\
h_{1, e f, \sigma}=\sqrt{\frac{h_{e f, w}^{3}}{h_{1}+2 \cdot \Gamma \cdot h_{s, 2}}} ; \quad h_{2, e f, \sigma}=\sqrt{\frac{h_{e f, w}^{3}}{h_{2}+2 \cdot \Gamma \cdot h_{s, 1}}},
\end{gathered}
$$

where: $h_{1}$, resp. $h_{2}$ - thickness of glass plate [mm]; $\Gamma$ - coefficient of shear forces [-]; $I_{s}$ - baricentrical inertia of two areas $A_{1}$ and $A_{2}\left[\mathrm{~mm}^{3}\right]$; and $h_{s, i}$ - modified values of thickness [mm]. Analytical relations for $I_{s}$ and $h_{s, i}$ could be found in (Galuppi et al., 2012a).

\section{Enhanced effective thickness method (EET)}

This enhanced method is based on a variational approach and it was originally constructed for the case of onedimensional laminated glass panes. The main idea of this method lies in finding the best approximation of the deflected shape of the pane minimizing the value of its strain energy functional, as Lagrange condition requests. The default shape function is considered in the form of the elastic curve of a monolithic pane with the constant cross-section in the same loading and boundary conditions of the problem at hand. This method was further extended for the twodimensional case of double laminated glass panes (Galuppi, Manara, \& Carfagni, 2012b). Minimization of the strain energy of the deflected laminated glass pane enables to determine the value of non-dimensional parameter $\eta$ analogous to $\Gamma$ coefficient in W-B method taking the values from 0 to 1.0. Parameter $\eta$ is written in the form of Eq. (6) (Galuppi et al., 2012b) as:

$$
\eta=1 /\left(1+\frac{t}{G} \cdot \frac{D_{1}+D_{2}}{D_{t o t}} \cdot \frac{12 \cdot D_{1} \cdot D_{2}}{D_{1} \cdot h_{2}^{2}+D_{2} \cdot h_{1}^{2}} \cdot \Psi\right),
$$

where: $D_{i}$ - the flexural rigidity of each glass plate [Nmm]; $t$ - the thickness of the interlayer [mm]; $G$ - shear stiffness of the interlayer [MPa]; $D_{\text {tot. }}$ - the flexural rigidity of the monolithic pane [Nmm] (Galuppi et al., 2012b); and $\psi$ is the shape coefficient capturing the loading and boundary conditions $\left[\mathrm{mm}^{-2}\right]$ (Galuppi et al., 2012a).

Input parameters for the response of double laminated glass pane by EET method are displayed in Figure 3. The effective thickness of the deflection $h_{e f, w}$ and normal stress $h_{j, \text { ef, } \sigma}(j \in\{1,2\})$ is calculated according to Eq. (7) and Eq. (8), respectively:

$$
\begin{gathered}
h_{e f, w}=1 / \sqrt[3]{\frac{\eta}{h_{1}^{3}+h_{2}^{3}+12 \cdot I_{s}}+\frac{1-\eta}{h_{1}^{3}+h_{2}^{3}}} ; \\
h_{1, e f, \sigma}=1 / \sqrt[2]{\frac{2 \cdot \eta \cdot h_{s, 2}}{h_{1}^{3}+h_{2}^{3}+12 \cdot I_{s}}+\frac{h_{1}}{h_{e f, w}^{3}}} ; \quad h_{2, e f, \sigma}=1 / \sqrt[2]{\frac{2 \cdot \eta \cdot h_{s, 1}}{h_{1}^{3}+h_{2}^{3}+12 \cdot I_{s}}+\frac{h_{2}}{h_{e f, w}^{3}}},
\end{gathered}
$$

where $I_{S}$ - baricentrical inertia of both glass plates (Galuppi et al., 2012b).

There are also other enhanced analytical methods for the calculation of laminated glass such as Newmark's model, Secant stiffness approach, etc. (Gallupi \& Carfagni, 2012). These methods are also able to provide reliable results. 


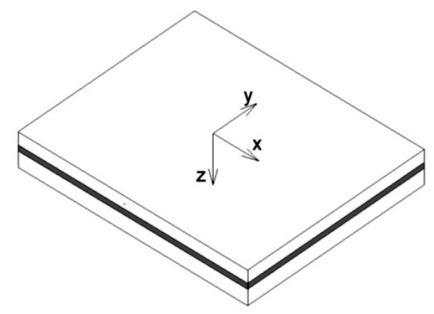

a) local coordinate system

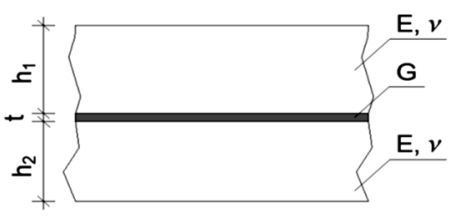

b) input parameters of materials

Figure 3. Input parameters for the calculation of double laminated glass pane by EET method

\section{Reclangular double laminated glass pane}

\section{Numerical FEM model in RFEM $5^{\circledR}$, boundary conditions of the solved pane}

Another way how to obtain a set of reliable results is to model a laminated glass numerically in some commercial FEM software such as ANSYS $\AA$, ABAQUS $\AA$, or RFEM ${ }^{\circledR}$. Each one requires a different level of designer's experience with numerical modeling. For the illustrated problem, 3D finite element model was created in software Dlubal RFEM $5 \AA$ - module RF Glass. The basic element of the mesh is solid 8-node brick with linear interpolation of displacement along the edge of the element. Each glass plate and the interlayer were meshed one by one with one element in a vertical sense. This density is a pre-set parameter and cannot be modified since this software was developed for quick engineering calculations. In spite of this, it is able to deliver reliable results (Hána, Eliášová, \& Sokol, 2018). Geometric parameters of the illustrated pane used in all calculations are as follows: interlayer thickness $t=0.76 \mathrm{~mm}$, thickness of glass plate $h_{1}=h_{2}=12 \mathrm{~mm}$, horizontal dimensions $2500 \times 2500 \mathrm{~mm}$, Young's modulus of glass $E=70 \mathrm{GPa}$, Poisson's ratio of the interlayer $v=0.45$ and of glass $v=0.23$. Glass and interlayer are considered as homogenous, isotropic, and elastic material. There is generally no information about the triaxial behaviour of most of interlayers. The basic step of the mesh in the horizontal direction was chosen as $25 \mathrm{~mm}$ thus each edge of the glass was divided into 100 elements. The width/height ratio of the interlayer element was 30 in order to avoid such shear locking effect (Molnár, Vigh, Stocker, \& Dunai, 2012). Part of the adopted mesh in the model and the detail of the mesh along the thickness of the pane are shown in Figure 4a and Figure 4b, respectively. In this study, there were considered four cases of double laminated glass panes in various boundary conditions: (i) continuously simply supported pane uniformly loaded by $1.0 \mathrm{kN} / \mathrm{m}^{2}$; (ii) continuously simply supported pane loaded by local force $1.0 \mathrm{kN}$ acting in the middle of the pane on the area of $50 \times 50 \mathrm{~mm}$; (iii) opposite-sides simply supported pane uniformly loaded by $1.0 \mathrm{kN} / \mathrm{m}^{2}$; and (iv) one edge fixed-ended pane uniformly loaded by $1.0 \mathrm{kN} / \mathrm{m}^{2}$. The way the panes were supported is shown in Figure 5 . Each support keeps the edge in place preventing the pane's corner lifting. Because of the relatively low value of the applied load, the calculation was performed by first order assuming small-displacement theory (Molnár et al., 2012).

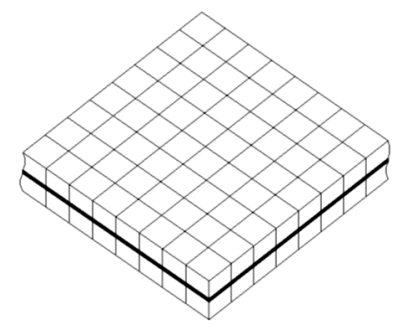

a) part of the mesh made of 8-node elements

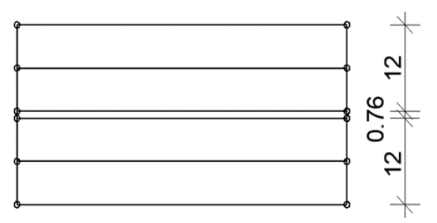

b) mesh along the thickness of pane

Figure 4. Adopted mesh in the numerical model

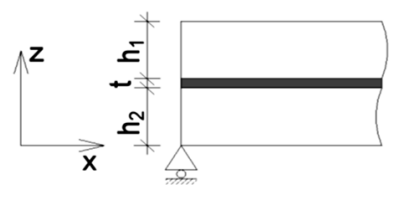

a) simple support in studied cases (i - iii)

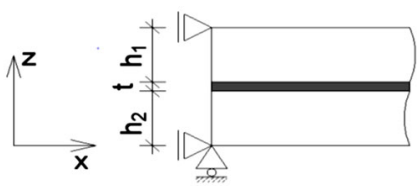

b) type of edge fixing - case (iv)

Figure 5. Type of constraint in the numerical model 


\section{Values of the effective thickness obtained analytically and numerically - case study}

To make a comparison between analytical and numerical methods, the shear modulus of the interlayer $G$ was varied between 0.01 to $140 \mathrm{MPa}$ with a step of $0.01 \mathrm{MPa}$. This corresponds to the temperature-dependent initial shear stiffness of commonly used PVB interlayer - Trosifol BG-R-20® (Hána, Eliášová, Machalická, \& Vokáč, 2017). The purpose of the study was to calculate the stress $h_{e f, \sigma}$ and the deflection $h_{e f, w}$ efective thickness of the individual glass plate for a certain value of the interlayer's shear stiffness. Since both plates of the pane are identical, the value of $h_{e f, \sigma}$ is identical too. In case of analytical methods, the calculation was performed according to the above procedures. In WB method, universal value $\beta=9.6$ was considered and the values of $\psi$ parameter in EET were found in (Galuppi et al., 2012a). In case of numerical model, the decisive peaks of stress and deflections were computed for the laminated glass pane with the representative value of $G$. And then, the corresponding value of $h_{e f, \sigma}$ or $h_{e f, w}$ was further calculated for a monolithic glass pane having the identical peaks of stress and deflections. This procedure was executed according to the ordinary formulas of these quantities available in a literature for these illustrated cases. Formulas consider linear plate theory and linearly elastic, isotropic material. For example, bending moments $m$ [Nmm] at the midspan and vertical deflection $w[\mathrm{~mm}]$ of the monolithic panes (i) and (ii) were calculated according to Eq. (9) and Eq. (10), respectively (Weller, Engelmann, Nicklish, \& Weimar, 2013) as

$$
\begin{aligned}
& m=\eta \cdot a \cdot b \cdot f ; \quad w=\frac{a^{2} \cdot b^{2}}{K} \cdot \eta_{f, q} \cdot f ; \\
& m=\eta \cdot Q ; \quad w=\frac{1}{A} \cdot \frac{a^{2} \cdot b^{2}}{K} \eta_{f, Q} \cdot q,
\end{aligned}
$$

where: $a$ and $b$ - ground dimensions of the pane [mm], $f$ - value of the uniform load $\left[\mathrm{N} / \mathrm{mm}^{2}\right], K$ - flexural rigidity of glass pane $[\mathrm{Nmm}], A$ - track of the local force $(50 \times 50 \mathrm{~mm}), Q-$ value of local force $[\mathrm{N}], q-$ value of uniform load $\left[\mathrm{N} / \mathrm{mm}^{2}\right]$ induced by local force $Q$ acting on the track A. Values of coefficients $\eta, \eta_{f, q}$, and $\eta_{f, Q}$ may be found in (Weller et al., 2013) for the appropriate loading and boudary conditions.

In case of pane (iii) and (iv), bending moments with resulting normal stress as well as vertical deflection were calculated according to generally well-known formulas for simply supported beam and cantilever. The following charts summarize the results of the case-study for different values of the interlayer's shear stiffness. Since each analytical method is calibrated for a certain boundary condition, numerical results will be considered as reference for percentage calculation of deviation.

Charts in Figure 6 show the results of uniformly loaded continuously simply supported pane (i). Straight lines express the values of effective thickness for different values of $\omega$ according to prEN 16612. In this draft, there is not any explicit relation between shear stiffness $G$ and $\omega$ coefficient since this is determined by "stiffness family" thus the lines are constant. But the values of both effective thicknesses for a certain $\omega$ value copy well those from FEM analysis because $\omega$ increases with increasing interlayer's shear stiffness (prEN 16613, 2013). Moreover, prEN 16612 was constructed for these boundary conditions. Both W-B and EET underestimate normal stress because they provide higher values of $h_{e f, \sigma}$ than FEM. To illustrate, for the value of $G=3.0 \mathrm{MPa}$, the difference between W-B and FEM is $8.0 \%$ and between EET and FEM it is 5.5\%. In case of deflections, W-B gives higher values of $h_{e f, w}-$ the deviation from FEM is up to $10.0 \%$.

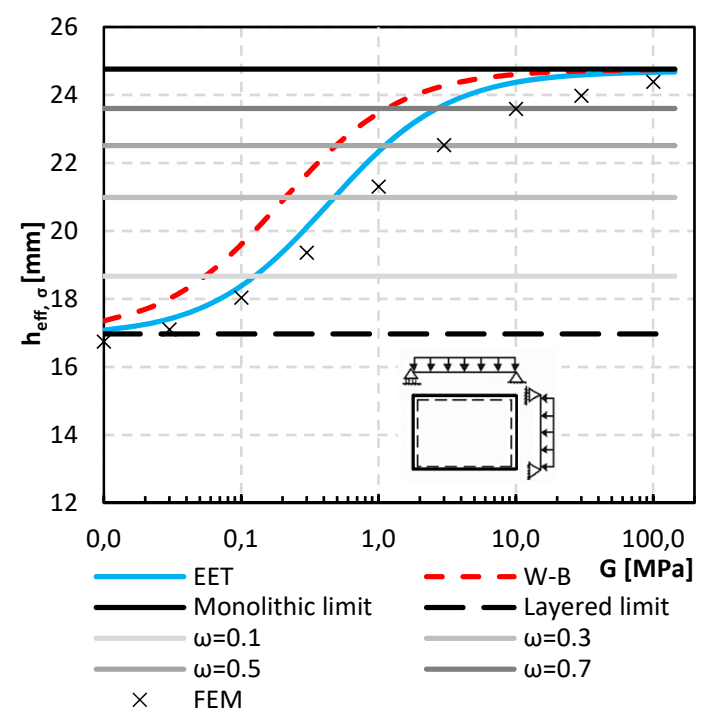

a) stress effective thickness

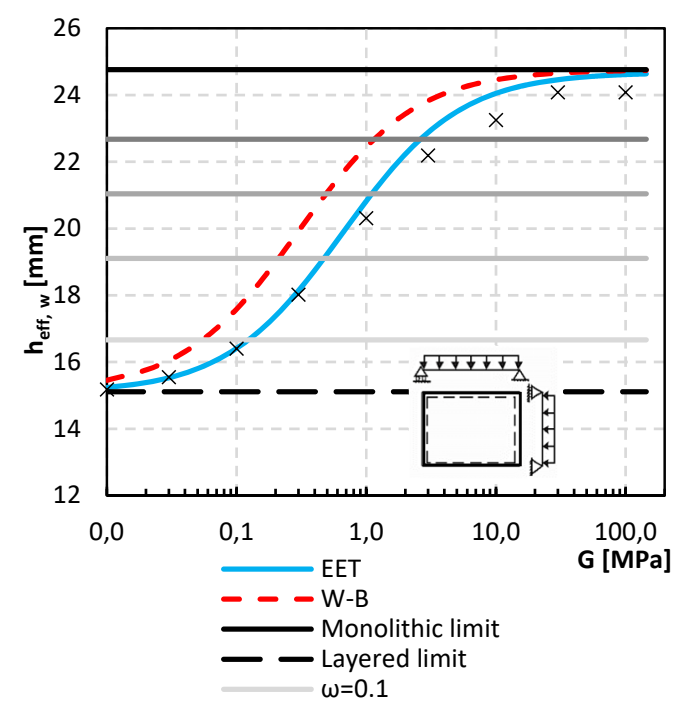

b) deflection effective thickness

Figure 6. Results for uniformly loaded continuously simply supported pane 


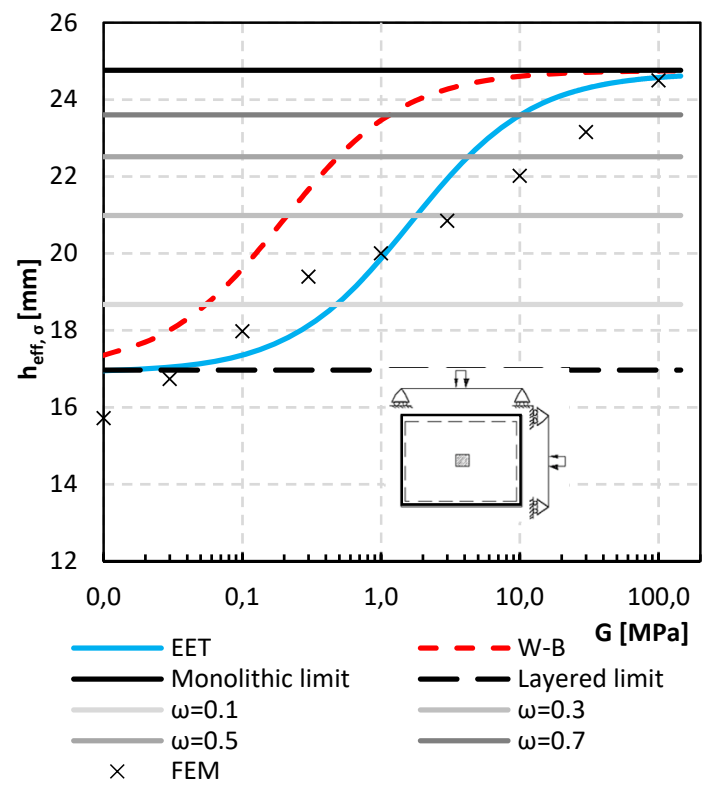

a) stress effective thickness

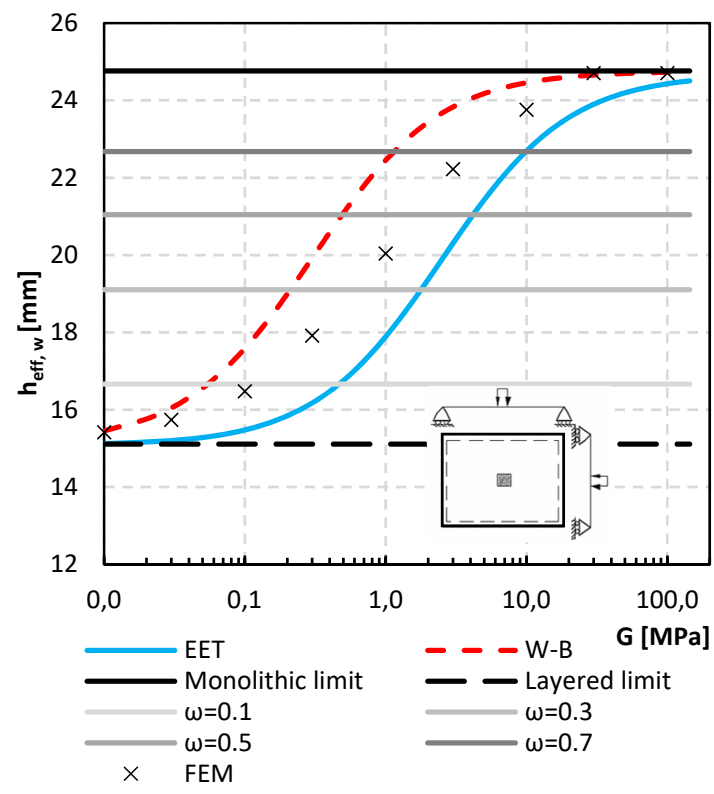

b) deflection effective thickness

Figure 7. Results for locally loaded continuously simply supported pane

Charts in Figure 7 show the results for the case of continuously simply supported pane loaded by local force (ii). In this case, the values of $h_{e f, \sigma}$ delivered by prEN 16612 are a bit overestimated, but vertical deflections copy well those by FEM as the value of $G$ increases. W-B rougly underestimates both normal stress and deflections. For example, the deviation of $h_{e f, \sigma}$ from FEM for $G=3.0 \mathrm{MPa}$ is $17.0 \%$ and in task of $h_{e f, w}$ for $G=1.0 \mathrm{MPa}$, the deviation is $12.0 \%$. EET method overestimates normal stress for the shear stiffness $G$ up to $1.0 \mathrm{MPa}$. For higher values of $G$ (e.g. shortterm loading, low temperatures), the situation is inverse. Vertical deflecions at the midspan by EET copy those by FEM in the entire interval but with a systematic safe deviation - to $11.0 \%$.

Results of this study for uniformly loaded opposite-sides simply supported pane (iii) are shown in Figure 8. Here, the enhanced analytical methods correlate well with numerical results. Even though this is a two-dimensional problem, W-B delivers almost accurate values of both effective thicknesses since the deflected shape is cylindrical. From all illustrated cases, the results based on the shape coefficient $\psi$ of panel (iii) as a part of EET show the best coincidence with FEM model. PrEN 16612 provides safe values of both quantities.

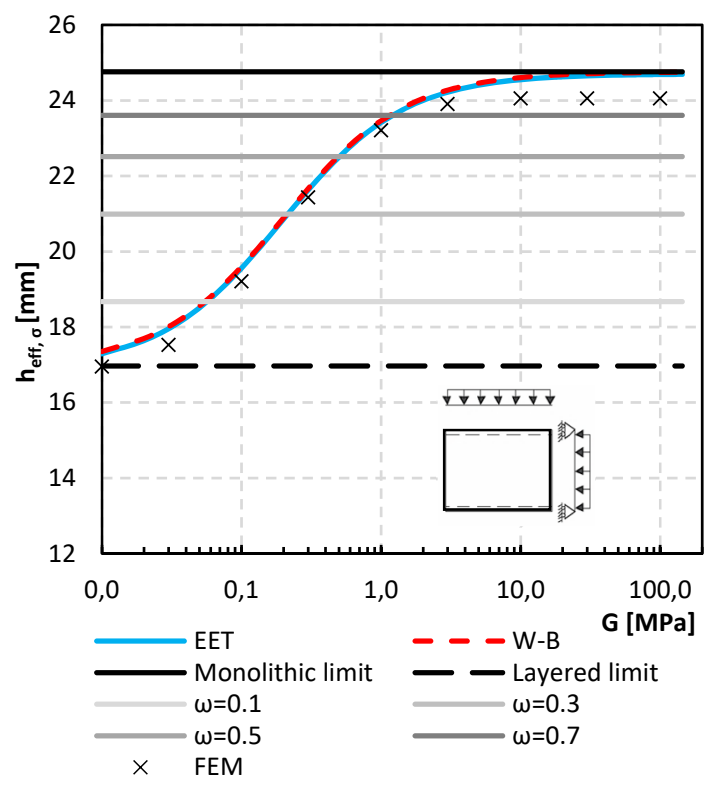

a) stress effective thickness

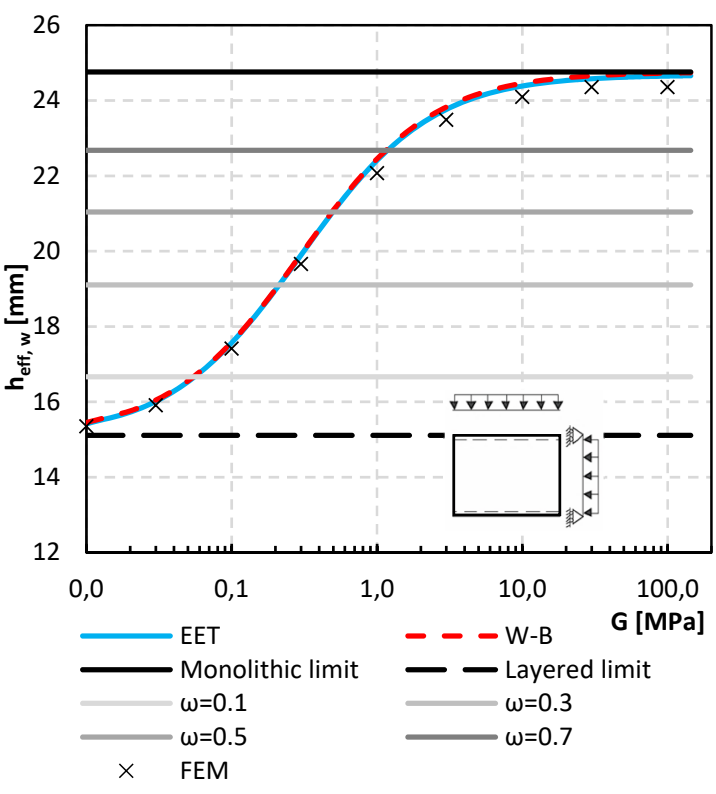

b) deflection effective thickness

Figure 8. Results for uniformly loaded opposite-sides simply supported pane 


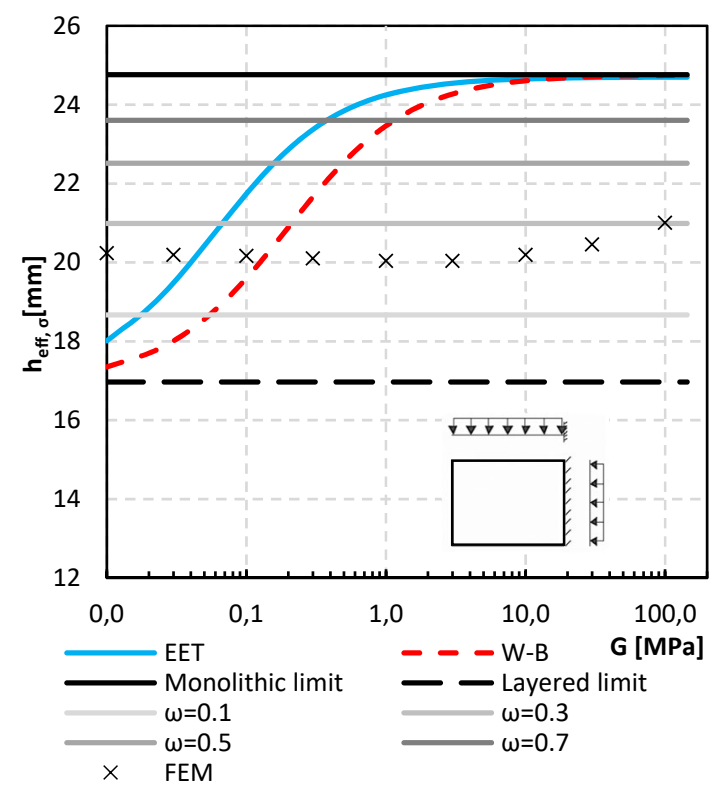

a) stress effective thickness

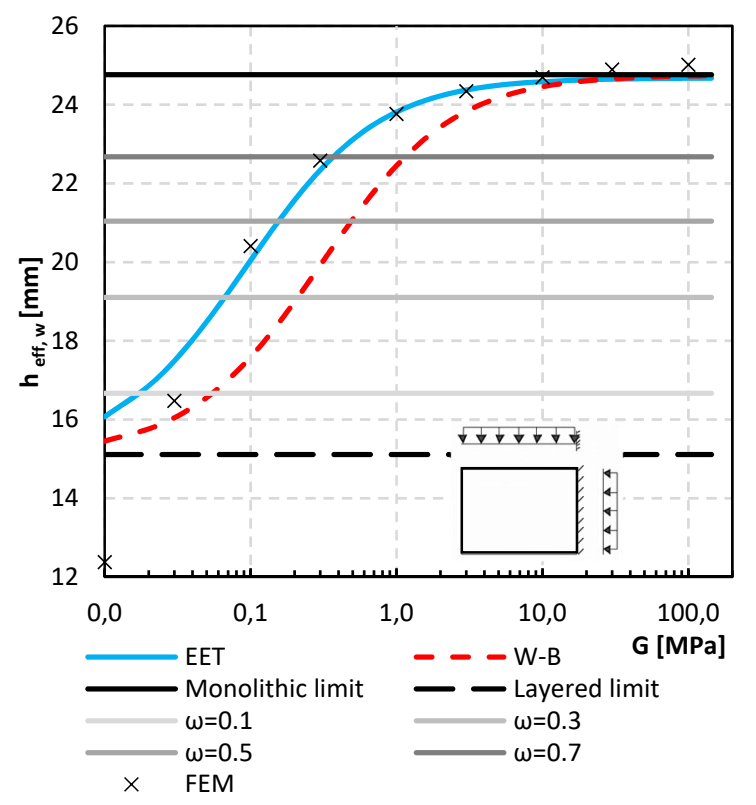

b) deflection effective thickness

Figure 9. Results for uniformly loaded one edge fixed-ended pane

Figure 9 shows the results for one edge fixed-ended uniformly loaded pane. Edge fixing is in the numerical model conservatively substituted by supports keeping the upper and lower edge of the pane fixed in a horizontal direction, see Figure $5 b$. The stress effective thickness by FEM is not $G$ sensitive since the horizontal reactions must be somehow transmitted. W-B provides safe values of $h_{e f, \sigma}$ for $G<0.1 \mathrm{MPa}$. For higher values of $G$, normal stress at fixing is underestimated by all presented analytical methods but the rate of discrepancy in a real structure is questionable. Vertical deflections of the free edge are well determined by EET. W-B delivers safe deviation of $h_{e f,}$ from FEM - to $14.0 \%$.

\section{Conclusions}

This paper provided a brief summary of current analytical methods such as Wölfel-Bennison, Enhanced Effective Thickness, and the draft of the standard prEN 16612, used for the analysis of laminated glass panes. All presented analytical methods taking the shear stiffness of the interlayer into account are based on the "effective thickness" of the monolithic pane with equivalent bending properties as the $j$-th glass plate in a composite. Case-study for several specific cases of square double laminated glass panes was illustrated. The study was based on the calculation of the effective thickness using presented analytical methods as the shear stiffness of the interlayer varied from 0.01 to $140 \mathrm{MPa}$. Considered cases were as follows: continuously simply supported uniformly loaded and locally loaded panes, opposite-sides simply supported uniformly loaded pane, and one edge fixed-ended uniformly loaded pane. Numerical model in RFEM 5 of all these panes was further constructed and the effective thickness based on numerical results was calculated. For the case of illustrated large size continuously simply supported panes, the coupling effects are well determined by prEN 16612 since this document was originally aimed at these structures, but it is not clearly mentioned in there. When the constraint is limited (opposite-sides simply supported pane of real dimensions), the results are conservative. In literature, there have been also illustrated cases of small size square continuously simply supported laminated panes where the effective thickness was not conservative (Galuppi \& Carfagni, 2013), the fact the designer should keep in mind. Based on obtained results, it is not advisable to use Wölfel-Bennison method for the calculation of two-dimensional case of panes since it was calibrated for one-dimensional uniformly loaded simply supported panes. EET method was able to capture the shear coupling in case of uniformly loaded simply supported panes but for the local force acting at the midspan, it provided unsafe results. All presented analytical methods provided rough deviations of stress at the support from the numerical approach in case of uniformly loaded one edge fixedended pane but the way the fixing was modeled, was such conservative. To obtain satisfactory results of stress at continuous fixing or at contact points, a full three-dimensional FEM analysis of a laminated panel with accurate inputs is necessary. To verify analytical and numerical results, large-scale experiments are possible. 
Hána, T.; Vokáč, M.; Eliášová, M.; Machalická, K. V. 2019. Advanced computational methods of perpendicularly loaded laminated glass panes

\section{Acknowledgements}

This research was supported by project MPO TRIO FV10295 and by SGS18/169/OHK1/3T/11.

\section{References}

American Society Testing of Materials. (2009). Standard practice for determining load resistance of glass in buildings (ASTM: E1300-09).

Bennison, S. J., \& Stelzer, I. (2009). Structural properties of laminated glass. Glass Performance Days. Tampere, Finland.

Calderone, I., Davies, P. S., Bennison, S. J., Huang, X., \& Gang, L. (2009). Effective laminate thickness for the design of laminated glass. Glass Performance Days. Tampere, Finland.

CEN. (2013). Glass in building - Determination of the load resistance of glass panes by calculation and testing (prEN 16612). Brussels.

CEN. (2013). Laminated glass and laminated safety glass - Determination of interlayer mechanical properties (prEN 16613). Brussels.

Deutsches Institute für Normung e.V. (2010). Glass in construction - Design and construction rules, Part 1: Terms and general principles (DIN 18008-1). Berlin.

Galuppi, L., \& Royer-Carfagni, G. F. (2012). Effective thickness of laminated glass beams: New expression via a variational approach. Engineering Structures, 38, 53-67. https://doi.org/10.1016/j.engstruct.2011.12.039

Galuppi, L., \& Royer-Carfagni, G. F. (2013). The effective thickness of laminated glass: Inconsistency of the formulation in a proposal of EN-standards. Composites: Part B, 55, 109-118. https://doi.org/10.1016/j.compositesb.2013.05.025

Galuppi, L., Manara, G., \& Royer-Carfagni, G. F. (2012a). Practical expressions for the design of laminated glass. Composites: Part B, 45(1), 1677-1688. https://doi.org/10.1016/j.compositesb.2012.09.073

Galuppi, L., Manara, G., \& Royer-Carfagni, G. F. (2012b). The effective thickness of laminated glass plates, Journal of Mechanics of Materials and Structures, 7(4), 375-400. https://doi.org/10.2140/jomms.2012.7.375

Hána, T., Eliášová, M., \& Sokol, Z. (2018). Structural performance of double laminated glass panels with EVA and PVB interlayer in four-point bending tests. International Journal of Structural Glass and Advanced Materials Research, 2, 164-177. https://doi.org/10.3844/sgamrsp.2018.164.177

Hána, T., Eliášová, M., Machalická, K., \& Vokáč, M. (2017). Determination of PVB interlayer's shear modulus and its effect on normal stress distribution in laminated glass panels. In IOP Conference Series: Materials Science and Engineering (vol. 251, conference 1). 012076. Riga. https://doi.org/10.1088/1757-899X/251/1/012076

Louter, Ch. (2011). Fragile yet Ductile: Structural aspects of reinforced glass beams (Dissertation thesis). Netherlands.

Molnár, G., Vigh, L. G., Stocker, G., \& Dunai, L. (2012). Finite element analysis of laminated structural glass plates with polyvinyl butyral (PVB) interlayer. Periodica Polytechnica Civil Engineering, 56(1), 35-42.. https://doi.org/10.3311/pp.ci.2012-1.04

National Research Council of Italy. (2012). Instructions for the design, execution and control of buildings with structural glass elements (CNR-DT-210). Roma.

Schneider, J., Langer, S., \& Schuster, M. (2015). Viscoelastic properties of laminated glass interlayers - Theory and experiments (pp. 143-147). Glass Performance Days. Tampere.

Serafinavičius, T., Lebet, J.-P., Louter, Ch., Lenkimas, T., \& Kuranovas, A. (2013). Long-term laminated glass four point bending test with PVB, EVA and SG interlayers at different temperatures. Procedia Engineering, 57, 996-1004. https://doi.org/10.1016/j.proeng.2013.04.126

Weller, R., Engelmann, M., Nicklish, F., \& Weimar, T. (2013). Glasbau Praxis - Konstruktion und Bemessung, Band 2. Beuth Verlag GmbH, Berlin. 